\title{
Size and function of the atria
}

\author{
B. J. M. Mulder · E. E. van der Wall
}

Received: 19 May 2008/Accepted: 19 May 2008/Published online: 4 June 2008

(C) The Author(s) 2008

Assessment of atrial size, anatomy and function is important in various clinical settings and can be performed with different imaging techniques. Assessment of atrial size provides important prognostic information and is routinely performed with transthoracic echocardiography. Information on regional atrial function can also be provided by transthoracic echocardiography and is important in the setting of treatment of atrial fibrillation. Catheter ablation procedures for atrial fibrillation require accurate imaging of the left atrium and surrounding structures. Intracardiac echocardiography, multislice computed tomography (CT), and cardiovascular magnetic resonance imaging (CMR) may provide detailed information on right and left atrium and pulmonary vein anatomy [1].

The atria perform three different functions during the various phases of the cardiac cycle, i.e. serving as reservoir during systole, passive conduit during early

B. J. M. Mulder

Department of Cardiology, Academic Medical Centre, Amsterdam, The Netherlands

B. J. M. Mulder

Department of Cardiology, University Medical Centre Utrecht, Utrecht, The Netherlands

E. E. van der Wall ( $\square)$

Department of Cardiology, Leiden University Medical Centre, Albinusdreef 2, 2333 ZA Leiden, The Netherlands e-mail: E.E.van_der_Wall@lumc.nl diastole, and booster function during late diastole. In this issue of the journal, Willens et al. report a descriptive study on the effects of age and pulmonary arterial hypertension on all three phases of right atrial function by measuring changes in right atrial volume during the cardiac cycle using two-dimensional transthoracic echocardiography [2]. In their study, Willens et al demonstrated that passive right atrial emptying was lower and booster function was greater in older healthy subjects and in patients with pulmonary arterial hypertension. Reservoir function was higher in pulmonary hypertension. These changes are analogous to the changes reported in the left atrium in response to increased afterload and impaired relaxation [3].

The active contractile component of the atria has an important role in patients with ventricular dysfunction to augment ventricular volume. Augmented atrial booster function is one of the mechanisms compensating for decreased early filling in patients with reduced ventricular compliance. Loss of atrial contraction as a result of atrial fibrillation or ventricular pacing reduces cardiac output by approximately 15-20\%. The ability to optimally redistribute ventricular filling among reservoir, conduit and booster pump functions is a potentially important adaptation that may occur in the atria in response to changing dynamics.

In patients with congenital or valvular heart disease, increased ventricular stiffness or decreased ventricular compliance may cause an increased atrial 
pressure. The increased atrial wall tension leads to stretch and dilation of the atrial myocardium. Thus, atrial volume increases with severity of diastolic dysfunction.

Atrial volume is a barometer of ventricular filling pressure and reflects the burden of diastolic dysfunction in subjects without atrial fibrillation or significant valve disease. Atrial enlargement carries important clinical and prognostic implications [1, 3]. In large population- based studies it has been demonstrated that left atrial size is an important predictor of cardiovascular outcome. Elevation of filling pressure is uniformly found in the presence of symptomatic congestive heart failure. Evidence for a prognostic role for left atrial volume to predict incident congestive heart failure is emerging [3]. In the general population left atrial size has been determined to be a predictor of stroke and death. The relationship between left atrial size and death has been demonstrated in high-risk groups, such as patients with dilated cardiomyopathy, left ventricular dysfunction, atrial arrhythmias, acute myocardial infarction, patients undergoing valve replacement for aortic valve stenosis and mitral regurgitation [3].

Left atrial size is potentially modifiable with medical therapy, but whether left atrial size reduction translates to improved outcomes remains to be established.

Atrial fibrillation is another important factor associated with atrial dilatation. Atrial enlargement may be the consequence of atrial fibrillation, but atrial enlargement may also lead to atrial fibrillation $[1,3]$. To what extent the shifts among reservoir, conduit and booster pump functions of the atria contribute to the development of atrial arrhythmias warrants further study.

The atria play an important role in adult congenital heart disease [4]. Atrial function is often altered due to longstanding pressure or volume overload. Moreover, many adult patients with a congenital heart defect have had intracardiac surgery with the use of cardiopulmonary bypass in the past. These patients will all have a right atrial scar, the sequel of the atriotomy necessary for the cannulation for the cardiopulmonary bypass or necessary for visualisation of intracardiac structures. This scarring leads to loss of atrial compliance and compromises atrial reservoir function. Moreover, atrial function can be substantially modified by some forms of surgical correction or palliation, such as the Mustard or Senning procedure in patients with transposition of the great arteries or a Fontan operation in patients with univentricular hearts [5-10]. Cardioplegic arrest may also cause deterioration of right atrial function. Altered caval vein flow patterns indicate abnormal atrial filling and the reservoir function of the right atrium is diminished postoperatively. Both the longstanding atrial overload and the atrial scarring form substrates for atrial arrhythmias. Loss of atrial reservoir function (reduced compliance) and the loss of booster function (atrial fibrillation) is poorly tolerated in patients with a compromised ventricular function.

In patients with right ventricular hypertrophy, such as in pulmonary arterial hypertension or in corrected tetralogy of Fallot, the forceful right ventricular contraction leads to an increased downward displacement of the tricuspid valve annulus, thereby increasing atrial filling from the pulmonary veins during systole. The antegrade pulmonary flow during diastole is decreased due to a decreased compliance. The higher filling pressures will cause a more forceful atrial contraction. Right ventricular volume overload, due to pulmonary regurgitation and/or tricuspid regurgitation in Fallot patients will also elevate right atrial pressure and volume. Either due to elevated right ventricular pressure or as a result of increased right ventricular volume, the right atrial wall is often stretched in patients with corrected tetralogy of Fallot. This will not only lead to an altered atrial function, but also to a high prevalence of atrial arrhythmias. In case of atrial fibrillation, the contribution of the atrial booster will then disappear, which may substantially worsen the hemodynamic status in these patients [11-22].

The longterm prognosis of adult patients with congenital heart disease is insufficiently known and largely dependent on right-sided cardiac function [23-26]. Noninvasive follow-up modalities are of utmost importance for these patients, in order to allow early detection of pressure or volume overload of the right ventricle before the occurrence of failure or irreversible myocardial damage. Early detection of right ventricular dysfunction may allow timely medical management and preventive surgery. CMR provides the diagnostic imaging of choice for the evaluation of right sided heart anatomy and function in congenital heart disease by its potential to obtain 
both anatomic detail and flow quantification [27-29]. CMR is useful for detecting intra- and extra-cardiac conduit obstruction following cardiac surgery in complex congenital heart disease. Technical advances of CMR are the excellent spatial resolution, the characterisation of myocardial tissue, multiplane versatility and the potential for three-dimensional imaging. By means of dobutamine stress cardiac reserve may be determined in various forms of congenital heart disease. In addition, the use of plasma neurohormones may play a role in early detection of cardiac dysfunction in asymptomatic patients with congenital heart defects [30-35].

The utility of atrial volume and function for monitoring cardiovascular risk and for guiding therapy becomes increasingly clear and may prove to have an important impact in clinical decision making.

Open Access This article is distributed under the terms of the Creative Commons Attribution Noncommercial License which permits any noncommercial use, distribution, and reproduction in any medium, provided the original author(s) and source are credited.

\section{References}

1. Tops LF, van der Wall EE, Schalij MJ, Bax JJ (2007) Multi-modality imaging to assess left atrial size, anatomy and function. Heart 93:1461-1470

2. Willens HJ, Fertel DP, Qin J et al (2008) Effects of age and pulmonary arterial hypertension on the different phases of right atrial function. Int $\mathrm{J}$ Cardiovasc Imaging. doi: 10.1007/s10554-008-9306-4

3. Abhayaratna WP, Seward JB, Appleton CP et al (2006) Left atruial size. Physiologic determinants and clinical applications. J Am Coll Cardiol 47:2357-2363

4. Meijboom F, Roos J, Sievert H (2002) The role of the atria in congenital heart disease. Cardiol Clin 20:351-366

5. Tulevski II, Van der Wall EE, Groenink M (2002) Usefulness of MRI dobutamine stress in asymptomatic and minimally symptomatic patients with decreased cardiac reserve from congenital heart disease. Am J Cardiol 89:1077-1081

6. Tulevski II, Lee PL, Groenink M et al (2000) Dobutamineinduced increase of right ventricular contractility without increased stroke volume in adolescent patients with transposition of the great arteries: evaluation with magnetic resonance imaging. Int J Card Imaging 16:471-478

7. Dodge-Khatami A, Tulevski II, Bennink GBWE et al (2002) Comparable systemic ventricular function in healthy adults and patients with unoperated congenitally corrected transposition using MRI dobutamine stress testing. Ann Thorac Surg 73:1759-1764

8. Tulevski II, Zijta FM, Smeijers AS, Dodge-Khatami A et al (2004) Regional and global right ventricular dysfunction in asymptomatic or minimally symptomatic patients with congenitally corrected transposition of the great arteries. Cardiol Young 14:168-173

9. Van der Zedde J, Oosterhof T, Tulevski II et al (2005) Comparison of segmental and global systemic ventricular function at rest and during dobutamine stress between patients with transposition and congenitally corrected transposition. Cardiol Young 15:148-153

10. Oosterhof T, Tulevski II, Roest AAW et al (2005) Disparity between dobutamine stress and physical exercise magnetic resonance imaging in patients with an intra-atrial correction for transposition of the great arteries. J Cardiovasc Magn Reson 7:383-389

11. Oosterhof T, Mulder BJM, Vliegen HW, De Roos A (2006) Cardiovascular magnetic resonance in the follow-up of patients with corrected tetralogy of Fallot: a review. Am Heart J 151:265-272

12. Tulevski II, Hirsch A, Dodge-Khatami A et al (2003) Effect of pulmonary valve regurgitation on right ventricular function in patients with chronic right ventricular pressure overload. Am J Cardiol 92:113-116

13. Oosterhof T, Meijboom FJ, Vliegen HW et al (2006) Longterm follow up of homograft function after pulmonary valve replacement in patients with tetralogy of Fallot. Eur Heart J 27:1478-1484

14. Neffke JGJ, Tulevski II, Van der Wall EE et al (2002) ECG determinants in adult patients with chronic right ventricular pressure overload due to congenital heart disease: relation with plasma neurohormones and MRI parameters. Heart $88: 266-270$

15. Oosterhof T, Vriend JWJ, Spijkerboer AM, Mulder BJM (2007) Cardiovascular magnetic resonance in a pregnant patient with absent pulmonary valve syndrome. Int J Cardiovasc Imaging 23:249-252

16. Engelfriet PM, Duffels MGJ, Möller T et al (2007) Pulmonary arterial hypertension in adults born with a heart septal defect: the Euro Heart Survey on adult congenital heart disease. Heart 93:682-687

17. Oosterhof T, Vliegen HW, Meijboom FJ et al (2007) Longterm effect of pulmonary valve replacement on QRS duration in patients with corrected tetralogy of Fallot. Heart 93:506-509

18. Duffels MGJ, Van Loon RLE, Berger RMF et al (2007) Pulmonary arterial hypertension associated with a congenital heart defect: advanced medium-term treatment stabilizes clinical condition. Congenit Heart Dis 2:242-249

19. Oosterhof T, Van Straten A, Vliegen HW et al (2007) Preoperative thresholds for pulmonary valve replacement in patients with corrected tetralogy of Fallot using cardiovascular magnetic resonance. Circulation 116:545-551

20. Duffels MG, Engelfriet PM, Berger RM et al (2007) Pulmonary arterial hypertension in congenital heart disease: an epidemiologic perspective from a Dutch registry. Int $\mathbf{J}$ Cardiol 120:198-204

21. Van Loon RL, Hoendermis ES, Duffels MG et al (2007) Long-term effect of bosentan in adults versus children with pulmonary arterial hypertension associated with systemicto-pulmonary shunt: does the beneficial effect persist? Am Heart J 154:776-782

22. Engelfriet P, Meijboom FJ, Boersma E et al (2008) Repaired and open atrial septal defects type II in 
adulthood: an epidemiological study of a large European cohort. Int J Cardiol 126:379-385

23. Engelfriet P, Boersma E, Oechslin E et al (2005) The spectrum of adult congenital heart disease in Europe: morbidity and mortality in a 5 year follow-up period. The Euro Heart Survey on adult congenital heart disease. Eur Heart J 26:2325-2333

24. Van der Velde ET, Vriend JWJ, Mannens MMAM et al (2005) CONCOR, an initiative towards a national registry and DNA-bank of patients with congenital heart disease in the Netherlands: rationale, design, and first results. Eur J Epidemiol 20:549-557

25. Engelfriet PM, Tijssen JGP, Kaemmerer H et al (2006) Adherence to guidelines in the clinical care for adults with congenital heart disease. The Euro Heart Survey on adult congenital heart disease. Eur Heart J 27:737-745

26. Moons P, Engelfriet P, Kaemmerer H (2006) Delivery of care for adult patients with congenital heart disease in Europe: results from the Euro Heart Survey. Eur Heart J 27:1324-1330

27. Tulevski II, Dodge-Khatami A, Groenink M (2003) Right ventricular function in congenital cardiac disease: noninvasive quantitative parameters for clinical follow-up. Cardiol Young 13:397-403

28. Tulevski II, Romkes H, Dodge-Khatami A et al (2002) Quantitative assessment of the pressure and volume overloaded right ventricular function: imaging is a real challenge. Int J Cardiovasc Imaging 18:41-51

29. Hoffmann A, Engelfriet P, Mulder BJM (2007) Radiation exposure during follow-up of adults with congenital heart disease. Int J Cardiol 118:151-153
30. Oosterhof T, Mulder BJM, Vliegen HW, De Roos A (2005) Corrected tetralogy of Fallot: delayed enhancement in right ventricular outflow tract. Radiology 237:868-871

31. Tulevski II, Bresser P, Hirsch A (2003) Decreased plasma neurohormones and improved cardiac performance after surgical treatment of chronic pulmonary embolism. Ann Thorac Surg 76:287-290

32. Oosterhof T, Tulevski II, Vliegen HW (2006) Effects of volume and/or pressure overload secondary to congenital heart disease (tetralogy of Fallot or pulmonary stenosis) on right ventricular function using cardiovascular magnetic resonance and B-type natriuretic peptide levels. Am J Cardiol 97:1051-1055

33. Tulevski II, Van Veldhuisen DJ, Mulder BJM (2002) Utility of a B-Natriuretic peptide as a marker for right ventricular dysfunction in acute pulmonary embolism. J Am Coll Cardiol 39:2080

34. Tulevski II, Ten Wolde M, Van Veldhuisen DJ (2007) Combined utility of brain natriuretic peptide and cardiac troponine $\mathrm{T}$ may improve rapid triage and risk stratification in normotensive patients with pulmonary embolism. Int $\mathbf{J}$ Cardiol 116:161-166

35. Tulevski II, Groenink M, Van der Wall EE (2001) Increased brain and atrial natriuretic peptides dysfunction in patients with chronic right ventricular pressure overload: correlation between plasma neurohormones and right ventricular dysfunction. Heart 86:27-30 